\title{
Investigation of the process of separation of hard-to-divide weeds from seed mixtures of perennial grasses
}

\author{
Stepan Kovalyshyn ${ }^{1}$ and Viktor Dadak ${ }^{1}$ \\ ${ }^{1}$ Lviv National Agrarian University, 80381, Dublyany, str. Volodymyra Velykoho 1, Ukraine
}

\begin{abstract}
The work is devoted to the study of seed separation process of perennial grasses on a pneumatic-electric separator. It highlights the main problems of their post-harvest treatment. The influence of the regulated parameters - the magnitude of the supply of seeds to the air-separator, the air flow rate and the electric field strength on the quality from the segregated seed material of the perennial rye-grass were determined by conducting a multifactorial experiment.

The optimal values of the regulated parameters of the pneumatic electric separation are substantiated, in which the content of heavy separating admixture of weeds in the seed mixture of perennial rye-grass is the least. It is proved that the use in the technological line of seed preparation of perennial grasses of the pneumatic electric separator allows to ensure the quality of the seed material of the perennial rye-grass in accordance with the requirements of the existing standards.
\end{abstract}

\section{Analysis of recent researches and publications}

In the structure of agricultural lands of Ukraine about 5 million hectares or $20 \%$ occupy areas under the cultures, which belong to the small-seeded. These include those whose masses of thousands of seeds are less than 5 grams [1]. These, in the main, are vegetable, oil and overwhelming majority of perennial legumes and herbs. The loss of high yields of these crops is not possible without the presence of sufficient quantities of high-quality seeds obtained in the process of postharvest treatment [2].

However, it is difficult to obtain seed material of perennial grasses of high quality in many cases, since it contains a large number of hard-to-divide impurities and biologically defective dead seeds, which differ little from the seeds of the culture by their basic physical and mechanical properties [2]. As a result, seed clearing machines used in the process of post-harvest treatment of mixtures of perennial grasses, can not provide for their qualitative cleaning. As a result, in some cases, during separation, a large number of conditioned crop seeds fall into waste, and in others it is impossible to separate the impurities of weeds.

The main reason for this situation is that in the vast majority of cleaning machines, separation of seed mixtures on the air-lattice-trier or friction working bodies is carried out. However, seeds of perennial grasses, especially ryegrass and its severely dispersed impurities of couch grass or lungwort, do not have a dominant feature of divisibility, since they differ little in size, form, and coefficient of friction. The lack of sufficiently effective means for their separation leads to a loss in the process of post-harvest processing of * Corresponding author: stkovalyshyn $@$ gmail.com conditioned (full-fledged) seeds, which reaches $20 \ldots$ $30 \%$ [3]. The increase in the yield of purified seeds, for example, perennial grasses only for $1 \%$ on a country scale is equivalent to an expansion of crops more than 20 thousand hectares [4].

In this regard, there is a need to develop machines that take into account not only the physical and mechanical properties of seeds, but also biological. To solve these problems during separation of the seed material of cereal grasses becomes possible by use of electric field in seed post-harvest separators, as an additional working body. According to Dadak [7], one of such machines can serve as a pneumatic electric separator, in which the separation of components of seed mixtures is carried out in aggregate of their electrical and aerodynamic properties [8].

\section{Setting objectives}

The aim of the work is to improve the quality of sowing material of perennial grasses due to the study of the process of pneumatic electric separation and the substantiation of the optimal parameters of the separator itself.

\section{The main material}

For experimental researches on separation of seed mixtures of perennial grasses of heavily dispersed impurities, an improved design of a pneumo-electric separator [8] was used, the general form of which is shown in Fig. 1a, and the technological scheme of his work - in Fig. 1b. 


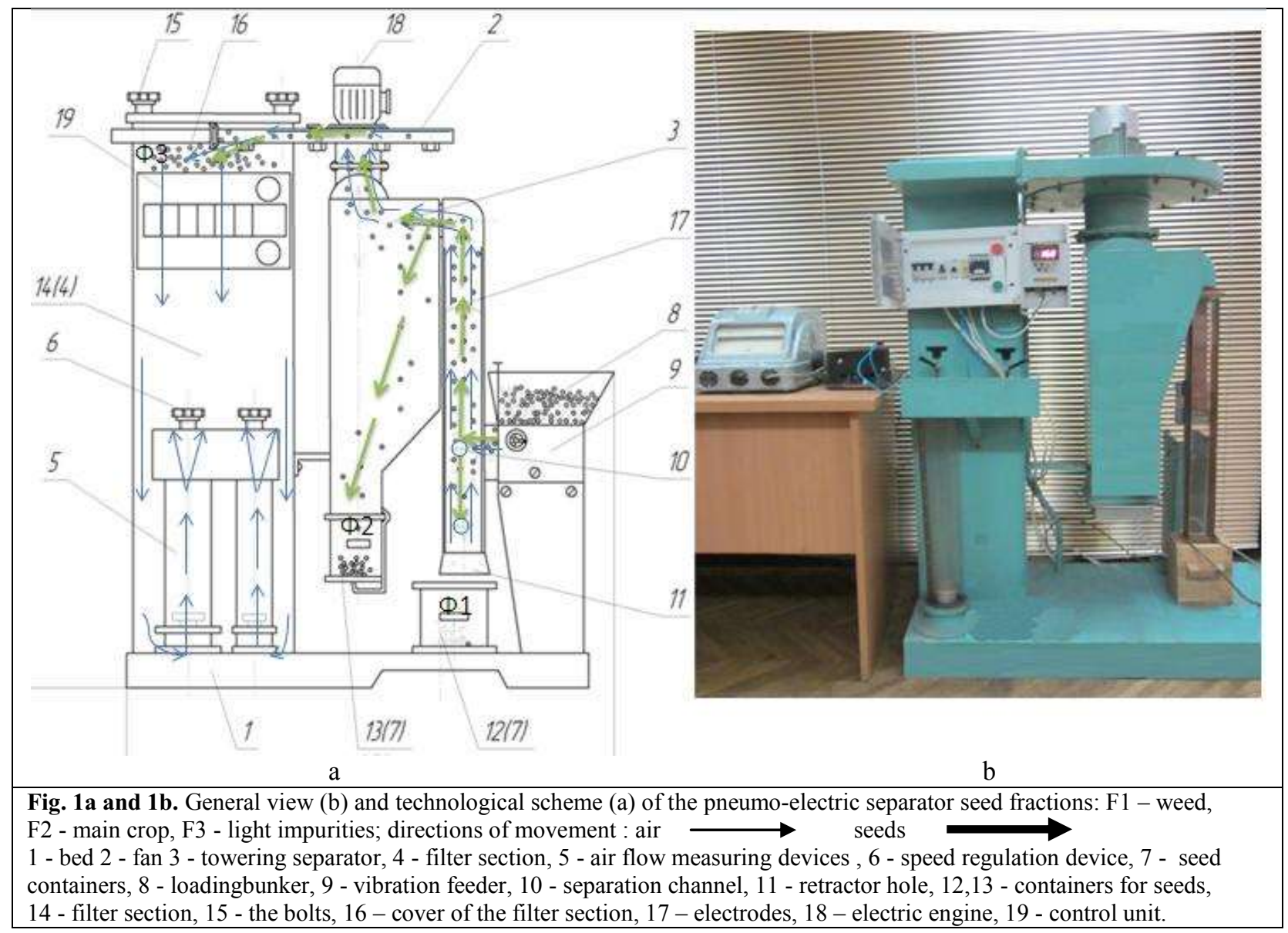

The peculiarity of this separator is the presence in theseparation channel 10 two electrodes 17 located opposite each other, which are fed with high voltage. Feedingof the separating mixture inloading bunker 8 to the separation channel 10 is carried out using a regulated vibration feeder 9 .

Investigation of the process of pneumatic electric separation of the seed material of perennial grasses was carried out through a multifactorial experiment. It determined the influence of the regulated parameters the values of the seeds feed $Q\left(\mathrm{~kg} \square \mathrm{h}^{-1}\right)$, the air velocity in the vertical separation channel $V_{n}(\mathrm{~m} / \mathrm{s})$, the electric field intensity $E(\mathrm{kV} / \mathrm{cm})$ in the separation zone on the quality indices of the sowing material that was expressed as a percentage of $K(\%)$ in it of qualitative seeds of the main culture.

Experiments were carried out using a seed mixture of perennial ryegrass, sort "Osip" II reproduction with a moisture content of $10 \%$ on a pneumatic electric separator with a vertical air channel [9].

The rate of air flow in the channel and its rotational speed is changed by the fan with frequency converter ASF 110.
The required electric field strength between the electrodes was achieved by changing the voltage applied to the electrodes 17.

During the experiments, the seed mixture was fed directly to the separating channel through a vibration dosing unit, which ensured a uniform initial rate of movement of individual seeds.

In the process of pneumatic electric separation, fractions of the separated seeds were obtained. Of these, samples were taken per 1000 seeds, counting the number of seeds of hard-to-divide weeds and determining their percentage content. The research was repeated - threefold. Each experiment corresponded to the specific values of the supply of seed material to the separator channel, the velocity of air in it and the intensity of the electric field.

Having analyzed the preliminary theoretical and experimental studies [15, 17], the zero levels of the investigated parameters of the pneumatic electric separation were established: the seed supply $X_{10}=3$ $\mathrm{kg} \square \mathrm{h}^{-1}$; speed of air flow $\mathrm{X}_{20}=6 \mathrm{~m} / \mathrm{s}$; the intensity of the electric field $X_{30}=1 \mathrm{kV} / \mathrm{cm}$. The results of their coding are shown in Table 1. 
Table 1. Results of coding of investigated factors.

\begin{tabular}{|c|c|c|c|c|c|c|c|c|c|}
\hline \multirow[b]{3}{*}{$\begin{array}{c}\text { Factors and units of } \\
\text { measurement }\end{array}$} & \multirow{3}{*}{ 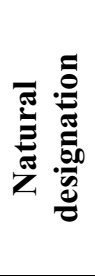 } & \multirow{3}{*}{ 롱 } & \multirow{3}{*}{ 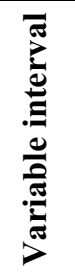 } & \multicolumn{6}{|c|}{ Levels of variation } \\
\hline & & & & \multicolumn{3}{|c|}{ natural } & \multicolumn{3}{|c|}{ coded } \\
\hline & & & & $\begin{array}{l}\text { I } \\
\vdots \\
\vdots \\
\vdots \\
\vdots \\
\vdots\end{array}$ & 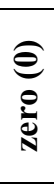 & $\begin{array}{l}\text { İ } \\
\vdots \\
0 \\
0\end{array}$ & $\begin{array}{l}\underset{7}{ \pm} \\
\vdots \\
\vdots \\
\vdots \\
\vdots\end{array}$ & 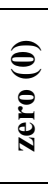 & $\begin{array}{l}\text { ت્} \\
\vdots \\
\vdots \\
0\end{array}$ \\
\hline 1 & 2 & 3 & 4 & 5 & 6 & 7 & 8 & 9 & 10 \\
\hline The seed supply, $Q, \mathrm{~kg} \square \mathrm{h}^{-1}$ & $X_{1}$ & $x_{1}$ & 1 & 4 & 3 & 2 & +1 & 0 & -1 \\
\hline Speed of air flow $V_{n}, \mathrm{~m} / \mathrm{s}$ & $X_{2}$ & $x_{2}$ & 0,5 & 6,5 & 6 & 5,5 & +1 & 0 & -1 \\
\hline $\begin{array}{l}\text { Intensity of the electric field } E \text {, } \\
\mathrm{kV} / \mathrm{cm}\end{array}$ & $X_{3}$ & $x_{3}$ & 0,15 & 1,15 & 1 & 0,85 & +1 & 0 & -1 \\
\hline
\end{tabular}

During the multifactorial experiment, the controlled parameter was the content of quality seeds of the main culture in the material under study. To find the coefficients of the polynomial, a three-level design of the second order of Box-Behnken was used. The matrix of the plan and the results of the multivariate experiment are shown in Table 2.

Table 2.Matrix plan and results of multi-factor experiment.

\begin{tabular}{|c|c|c|c|c|c|c|c|}
\hline \multirow{2}{*}{ № } & \multicolumn{3}{|c|}{ Value of coded factors } & \multicolumn{3}{c|}{$\begin{array}{c}\text { Results of determining the content of the } \\
\text { main culture in the separated samples, \% }\end{array}$} & $\begin{array}{c}\text { Average } \\
\text { value }\end{array}$ \\
\cline { 2 - 8 } & $\boldsymbol{x}_{\mathbf{1}}$ & $\boldsymbol{x}_{\mathbf{2}}$ & $\boldsymbol{x}_{\mathbf{3}}$ & $\begin{array}{c}\text { Sample } \\
\mathbf{1}\end{array}$ & $\begin{array}{c}\text { Sample } \\
\mathbf{2}\end{array}$ & $\begin{array}{c}\text { Sample } \\
\mathbf{3}\end{array}$ & \\
\hline $\mathbf{1}$ & -1 & -1 & 0 & 90 & 89 & 88 & 89 \\
\hline $\mathbf{2}$ & 1 & -1 & 0 & 86 & 88 & 90 & 88 \\
\hline $\mathbf{3}$ & -1 & 1 & 0 & 96 & 95 & 94 & 95 \\
\hline $\mathbf{4}$ & 1 & 1 & 0 & 80 & 82 & 84 & 82 \\
\hline $\mathbf{5}$ & -1 & 0 & -1 & 86 & 87 & 88 & 87 \\
\hline $\mathbf{6}$ & 1 & 0 & -1 & 88 & 90 & 92 & 90 \\
\hline $\mathbf{7}$ & -1 & 0 & 1 & 96 & 96 & 96 & 96 \\
\hline $\mathbf{8}$ & 1 & 0 & 1 & 89 & 88 & 90 & 89 \\
\hline $\mathbf{9}$ & 0 & -1 & -1 & 90 & 91 & 89 & 91 \\
\hline $\mathbf{1 0}$ & 0 & 1 & -1 & 93 & 92 & 92 & 92 \\
\hline $\mathbf{1 1}$ & 0 & -1 & 1 & 94 & 88 & 88 & 90 \\
\hline $\mathbf{1 2}$ & 0 & 1 & 1 & 95 & 92 & 92 & 93 \\
\hline $\mathbf{1 3}$ & 0 & 0 & 0 & 88 & 89 & 90 & 89 \\
\hline $\mathbf{1 4}$ & 0 & 0 & 0 & 91 & 93 & 89 & 91 \\
\hline $\mathbf{1 5}$ & 0 & 0 & 0 & 90 & 89 & 91 & 90 \\
\hline
\end{tabular}

As a result of processing of the obtained data of the multivariate experiment and the use of software Statistica 8.0, the regression equation for the content of seeds of the main crop in the sowing material of the perennial ryegrass was obtained:

- in coded notation:

$$
\begin{gathered}
K=97,45+0,0412 x_{1}-0,0425 x_{2}-0,5838 x_{3}+0,4175 \\
x_{1} x_{2}+0 x_{1} x_{3}+0,1675 x_{2} x_{3}-0,596 x_{1}{ }^{2}+0,0717 x_{2}{ }^{2}- \\
0,0171 x_{3}{ }^{2}
\end{gathered}
$$

- in natural values:

$$
\begin{gathered}
K=91,54+4,21 Q+3,72 V-18,85 E+0,417 Q^{2}- \\
0 V^{2}+7,444 E^{2}-1,192 Q V+0,478 Q E- \\
-0,228 V E .
\end{gathered}
$$

The randomized block designs of the experimental results were checked by the Cochran criterion. The hypothesis of the randomized block designs of experiments was taken if the calculated value of the $G_{p}$ criterion was less than its table value. In our case, the calculated value $G_{p}=0,173$, which is less than the table value $\left(G_{m}=0,3346\right)$. This indicates the randomized block designs of the experiment.

The equilibrium surface $(2,3,4)$ is constructed for equation (1), which determines the optimal parameters of the process of pneumatic electric separation. The function $K=f(E, Q)$ of the content dependence in the decoupled material of the seed of the main crop from the intensity of the electrostatic field in the separator channel 
and the supply of the seed mixture (Figure 3) acquires the maximum value at $0,4>\mathrm{Q}>0,4$ and $\mathrm{E}=-1$, which in natural quantities is $3,4>\mathrm{Q}>2,6 \quad \mathrm{~kg} \square \mathrm{h}^{-1}$ and $\mathrm{E}=$ $=0,85 \mathrm{kV} / \mathrm{cm}$.

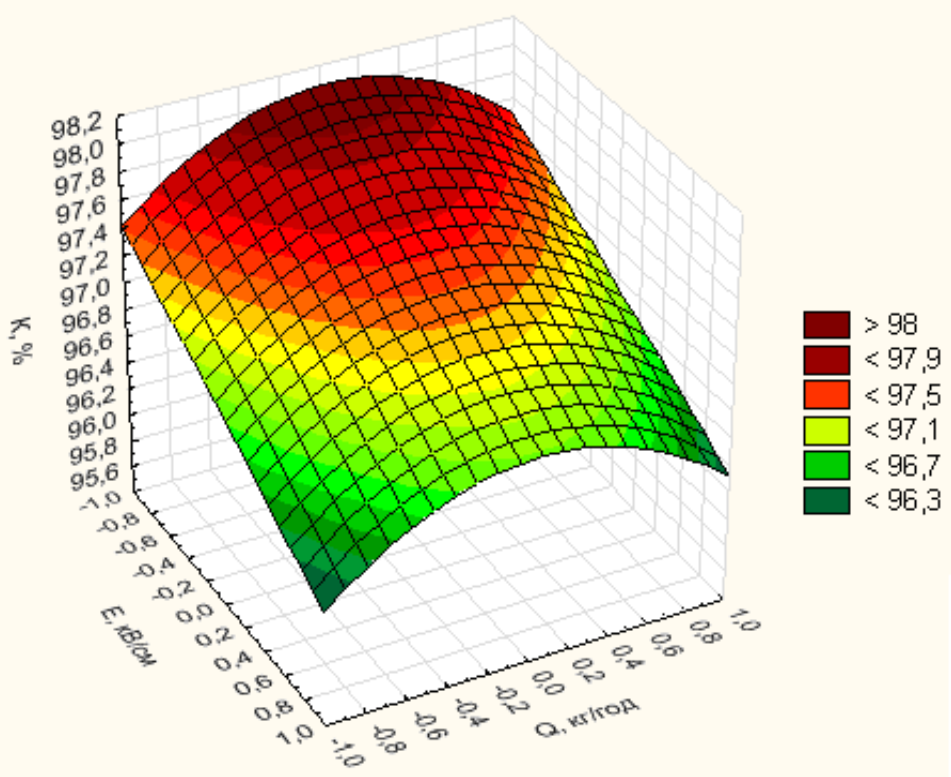

Fig.2.The equilibrium surface $K=f(E, Q)$.

Under such a separator operation, the seed content of the main culture reached $K=97 \ldots 98,2 \%$.

The function $K=f(Q, V)$ of the dependence of the content of seeds of the main crop on the velocity of the air flow in the separator channel and the supply of the seed mixture (Figure 3) acquires a maximum value at $0,2>\mathrm{Q}>0,2$ and $\mathrm{V}=0,8 \ldots 1$, which in physical quantities is 3,2>Q $>2,8 \mathrm{~kg} \square \mathrm{h}^{-1}$ and $\mathrm{V}=6,2 \ldots 6,5 \mathrm{~m} / \mathrm{s}$. For such parameters of the separator, the content of seeds of the main culture reaches $K=97,6 \%$.

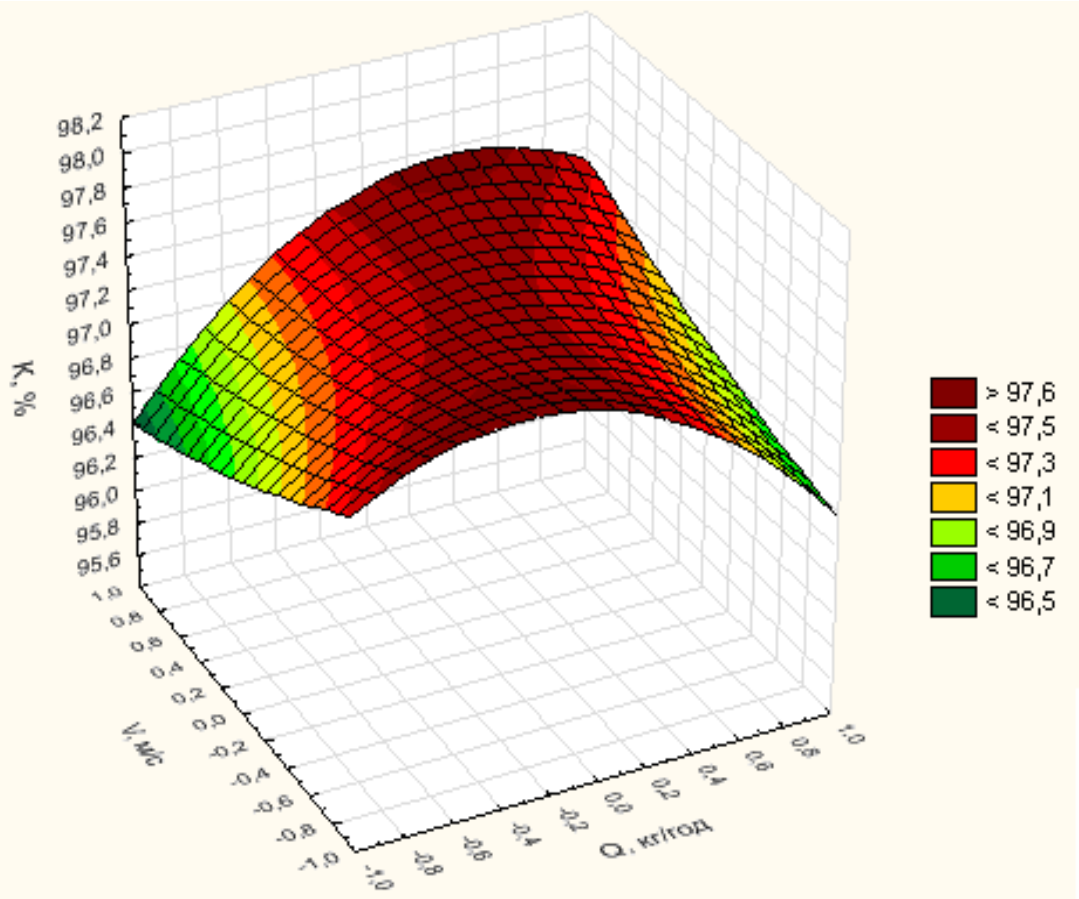

Fig.3.The equilibrium surface $K=f(Q, V)$.

The function $\mathrm{K}=\mathrm{f}(\mathrm{E}, \mathrm{V})$ of the dependence of the content of seeds of the main culture on the strength of the electrostatic field and the air flow velocity in the separator channel (Figure 4) acquires the maximum 
value at $E=-1$ and $V=-1$, which in natural quantities makes $E=0,85 \mathrm{kV} / \mathrm{cm}$ and $V=5,5 \mathrm{~m} / \mathrm{s}$.
Under such a separator operation, the seed content of the main culture reached $K=98 \%$.

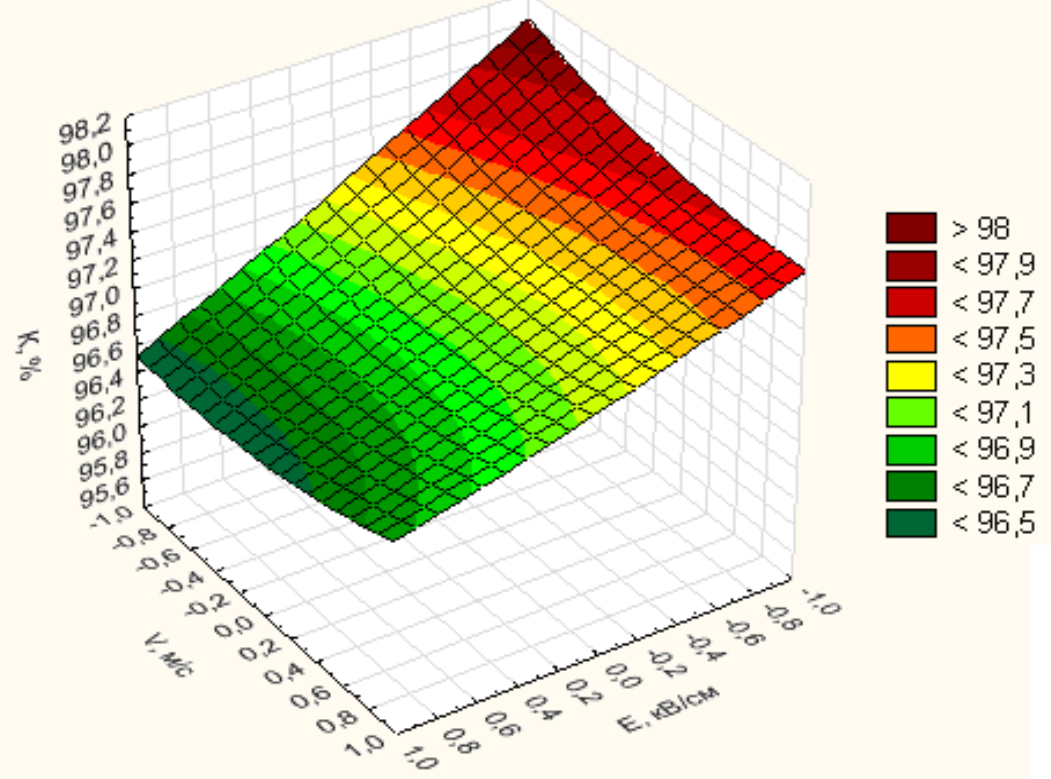

Fig.4.The equilibrium surface $K=f(E, V)$.

The adequacy of the results obtained is checked by Fischer's criterion. Estimated value of which is $F=$ $=0,877$. Its tabular value for this case will be $F_{m}=2,12$. Since the calculated value of Fisher's criterion is smaller than the tabular one, it can be argued that this model is adequate.

The analysis of the above results allowed to determine the optimal values of the regulated parameters of the pneumo-electric separator, which yields the bestquality seed material. In order to ensure the maximum efficiency of the separation from the perennial ryegrassof hard-to-divide impurities, it is necessary to ensure the velocity of the air flow $V_{n}=5,5 \ldots 6,2 \mathrm{~m} / \mathrm{s}$, the electrostatic field strength in the separation channel $E=$ $=0,85 \ldots 0,92 \mathrm{kV} / \mathrm{cm}$, the supply of a seed mixture $Q=2 \ldots 3,2 \mathrm{~kg} \square \mathrm{h}^{-1}$.

For the indicated parameters of the separator, the content of seeds of the main culture was $K=97 \ldots$ $98,2 \%$, and was in compliance with the requirements of DSTU 7160: 2010 "Seeds of vegetable, melon, coriander and spicy aromatic cultures. Varietal and sowing quality. Specifications ", according to which this indicator should be $90 \ldots 95 \%$.

\section{Conclusions}

1. The quality of the process of pneumatic electric separation of seed mixtures of perennial ryegrass has a significant influence on the investigated adjustable parameters: air flow velocity, seed feed rate, and the strength of the electrostatic field.

2. By conducting a multifactorial experiment, optimal modes of operation of the separator were determined, in which the maximum separation of hard-to-divide separating impurities from the investigated seed mixture is achieved: the velocity of the air flow
$V_{p}=5,5 \ldots 6,2 \mathrm{~m} / \mathrm{s}$; The intensity of the electrostatic field in the separation channel $E=0,85 \ldots 0,92 \mathrm{kV} / \mathrm{cm}$; supply of seed mixture $Q=2 \ldots 3,2 \mathrm{~kg} \square \mathrm{h}^{-1}$.

3 . The use of the proposed pneumatic separator in the production line for the preparation of seeds of perennial grasses, in particular, the perennial ryegrass, allows us to significantly improve the quality of the received sowing material and to bring the content of hard-to-divide weeds in accordance with DSTU 7160: 2010 "Seeds of vegetable, melon, coriander and spicy aromatic cultures. Varietal and sowing quality. Specifications ".

\section{References}

1. S.Y. Kovalyshyn. The Bulletin of Agrarian Science. №10. - P. 71-74. (1998)

2. S.Y. Kovalyshyn. Agricultural machines. - Collection of scientific articles. - Issue 4. - Lutsk, P. 69-73. (1998)

3. S.Y. Kovalyshyn. Substantiation of technological parameters of seed treatment of perennial grasses by electrovibrator separator: Dis. Cand. Tech Sciences: 05.20.01. - Lviv. 178p. (1999)

4. V.O. Paranyuk. Separation of seed mixtures in an electric field on a moving with constant speed of an inclined plane: Dis. Cand. Tech. Sciences: 05.20.02. - Chelyabinsk. 152p.(1983)

5. P. M. Zaika. Moscow: Kolos. 280 p.1978.

6. S. Y. Kovalyshyn, V.O. Dadak. Bulletin of the Kharkiv National Technical University of Agriculture named after Petro Vasilenko, "Technical systems and technologies of animal husbandry". Ed. 144. P. 225-232. (2014) 
7. V.O. Dadak. Mechanization and electrification of agriculture: Inter-departmental thematic scientific collection. Ed. 97, Volume 2, Glevaha. P. 495501.(2013)

8. S. Y. Kovalyshyn. V.O. Paranyuk, V.O. Dadak. Scientists of Lviv. Nats Agr University of Production: catalog of innovative developments. Ed. XIII. Lviv.P. 48.(2013)

9. V. V. Shmigel. Mehanization and electrification of agriculture №2 / power supply, electric drive and electrotechnology. P. 37-38.(1978)

10. O. P. Shvets. Justification of parameters and modes of operation of separator of winter rape seed. Author's abstract Dis For obtaining sciences. Candidate Degree Tech Sciences. Lviv. 20 p.(2012)

11. V. G. Khamuyev. Engineering in agriculture. No. 5. P. 23-26.(2008)

12. A.K. Turov. Engineering in agriculture. № 2, (2013)
13. V.O. Paranyuk, S.Y. Kovalyshyn, V.I. Melnychuk. Techno-technological aspects of development and testing of new technology and technologies for agriculture $O f$ Ukraine. $Z b$ Sciences Etc. UkrNDIPVT them. L. Burned: Vip. 10 (24), K. 1. Research. - P. 77-86. (2007)

14. Seeds of vegetable, melon, fodder and spicy-aromatic crops. Varietal and sowing quality. Technical specifications: DSTU7160: 2010 [Effective from 2010-07-01]. - K .: National standard of Ukraine. 19 p. (2010)

15. S. Y. Kovalyshyn, V.O. Paranyuk, V.O. Dadak. Motrol: Motorization and power industry in agriculture - Lublin: Comission of motorization and power industry in agriculture - Vol. 14D. P. 95-103. (2012)

16. V. P. Yermak, Ye. V. Bogdanov, A. A. Ilchenko. Collection of scientific works of Luhansk National Agrarian University.Series (Technical sciences.) Lugansk: LNAU - P. 127-132. (2012) 